Citation: Uğurlu, Ö.Y., \& Kızıldağ, D., \& Tufan, C., A Model Proposal Regarding Antecedents and Outcomes of Unlearning: Case Study of an R\&D Firm From Turkey, BMIJ, (2020), 8(5): 4300-4332 doi: http://dx.doi.org/10.15295/bmij.v8i5.1643

\title{
A MODEL PROPOSAL REGARDING ANTECEDENTS AND OUTCOMES OF UNLEARNING: CASE STUDY OF AN R\&D FIRM FROM TURKEY
}

\author{
Özlem Yaşar UĞURLU 1 \\ Duygu KIZILDAĞ ${ }^{2}$ \\ Cenk TUFAN ${ }^{3}$
}

\author{
Received Date (Başvuru Tarihi): \\ Accepted Date (Kabul Tarihi): \\ Published Date (Yayın Tarihi):
}

$29 / 09 / 2020$

$23 / 11 / 2020$

$25 / 12 / 2020$

In the article, the first author is in the role of Corresponding Author.

\section{ABSTRACT}

Keywords:

Unlearning,

Antecedents of Unlearning,

Organizational Learning,

Innovation

JEL Codes:

M10, 031, 032

In the literature, the subject of unlearning is discussed less than organisational learning and learning organisation. Thinking the dynamics of today's economy and the business world, having an unlearning ability is especially important for firms that focus on innovation and sustainable development. This research aims to explore the process of unlearning in an innovative company with a high capability of RED, to determine the type of unlearning and its antecedents affecting the unlearning process, and also to find the positive outcomes of unlearning for the company and to establish a model as a result of these findings. In line with the purpose of the research, this investigation was undertaken by using the case study method and doing semistructured interviews with company officials in an RED company that offers advanced technological products and services to the defence, environment and energy industries in Turkey. According to the research findings, it is seen that company $A$ can unlearn and the processes related to unlearning. When the findings obtained in terms of the unlearning process and its subdimensions are combined, it is noteworthy that the company sees unlearning at the centre of development and improvement. A model was proposed through the findings.

\section{GERİ ÖĞRENMENİN ÖNCÜLLERİ VE SONUÇLARI İLE İLGİLİ BİR MODEL ÖNERİSI: TÜRKIYYE'DE BİR AR-GE FİRMASINDA ÖRNEK OLAY İNCELEMESİ}

$\ddot{O Z Z}$

Anahtar

Kelimeler:

Geri Öğrenme,

Geri

Öğrenmenin

Öncülleri,

Örgütsel

Öğrenme,

İnovasyon

JEL Kodlari:
Alanyazında geri ögrenme konusu örgütsel öğrenme ve ögrenen örgütlerden daha az tartışılmaktadır. Günümüz ekonomisinin ve iş dünyasının dinamikleri düşünüldüğünde, geri ögrenme yeteneğine sahip olmak, özellikle inovasyona ve sürdürülebilir gelişmeye odaklanan firmalar için önemlidir. Bu araştırmanın amacl, yüksek Ar-Ge yeteneğine sahip inovatif bir şirkette geri öğrenme sürecini araştırmak, geri öğrenme türünü ve geri öğrenme sürecini etkileyen öncülleri belirlemek, şirket için geri öğrenmenin olumlu çıktılarını bulmak ve bu bulgular sonucunda bir model oluşturmaktır. Araştırmanın amacı doğrultusunda, Türkiye'de savunma, çevre ve enerji sektörlerine ileri teknolojik ürün ve hizmetler sunan bir Ar-Ge şirketinde örnek olay incelemesi yöntemi kullanılarak ve şirket yetkilileriyle yarı yapılandırılmış görüşmeler yapılarak bu araştırma gerçekleştirilmiştir. Araştırma bulgularına göre, araştırmada incelenen A Firmasının geri öğrenme becerisine ve ilgili süreçlere sahip olduğu görülmektedir. Geri öğrenme süreci ve alt boyutları açısından elde edilen bulgularun tümü birleştirildiğinde işletmenin geri öğrenme kavramına oldukça önem verdiği, gelişim ve iyileştirmenin merkezinde gördüğ̈̈ dikkati çekmektedir. Elde edilen bulguların sonucu olarak bir model önerilmiştir.

M10, 031, O32

\footnotetext{
${ }^{1}$ Doç. Dr., Gaziantep Üniversitesi, İ.̇̇.B.F.., İşletme Böl, yasar@gantep.edu.tr,

https://orcid.org/0000-00015165-5603

2 Prof. Dr., İzmir Demokrasi Ünv., İ.İ.B.F., İnsan Kayn.Yön. Böl., duygu.kizildag@idu.edu.tr , https://orcid.org/0000-0001-5354-7729

${ }^{3}$ Dr.Öğr. Üyesi, Akdeniz Üniversitesi, U.B.F., Havacilık Yön. Böl, cenktufan@akdeniz.edu.tr, https://orcid.org/0000-0002-2809-3996
} 


\section{INTRODUCTION}

Whether companies may achieve sustainability by obtaining positive outcomes such as growth, innovation, customer retention, and maximisation of value in a dynamic business environment conditions, depends on their ability to update and develop their skills by adopting continuous improvement. Improving R\&D and innovation performance by accessing new knowledge and transforming obtained knowledge into different products and services is seen as an essential dynamic capability for businesses. Companies require more than one skill and talent in order to sustain their skills by transferring innovation to their activities and produce economic value (Zahra, Abdelgawad, and Tsang, 2011). The capability of companies to provide and maintain these emotional skills is directly related to their capability to renew individual and organisational knowledge and to adapt to change (Zhao, Lu, and Wang, 2013). This revitalising and healing activity is defined as unlearning (Herdberg, 1981).

Unlearning is considered as an essential condition for organisations in order to adapt to environmental changes successfully, to promote organisational learning and to improve the performance of a company (Tsang and Zahra, 2008). The unlearning process occurs at both individual and organisational levels. Individual unlearning specifies the capacity of individuals to identify the activities that provide performance improvement and reflect this within their performance (CegarraNavarro and Rodrigo-Moya, 2005). Organisational unlearning is explained, by the authors who use this term, referring to both the processes of abandoning old methods and adopting new behaviours, ideas or actions by the individuals. In this context, organisational unlearning is seen as one of the necessary skills required to abandon obsolete mental models and as capacity development for continuous organisational innovation (Mieres, Sánchez, and Vijande, 2012).

Although the concept of organisational unlearning has been used since the end of the 2000s, unlike organisational learning, it is rarely included in empirical research (Akgün, Lynn, and Byrne, 2006; Akgün, Byrne, Lynn, and Keskin, 2007; Tsang and Zahra, 2008). Although examiners have examined a few cases of 
organisational unlearning (Mehrizi and Lashkarbolouki, 2016), how possible is it to unlearn the old methods to adapt to the new reality and the impact of unlearning on employees have been under-researched (Snihur, 2018; Tsang and Zahra, 2008).

This research, which is expected to contribute to the unlearning literature, aims to explore the positive outcomes of unlearning for the company by examining the antecedents that affect the unlearning process of the company in the individual, group and organisational contexts. In line with this purpose, this investigation was undertaken by using the case study method and doing semi-structured interviews with company officials in an R\&D company that offers advanced technological products and services to the defence, environment and energy industries in Turkey.

\section{LITERATURE REVIEW}

\subsection{Organizational Unlearning}

Organisational unlearning is a compelling process in which an organisation describes and removes any unnecessary, obsolete knowledge and routines that prevent it from acquiring and creating new knowledge (Cegarra-Navarro and Rodrigo-Moya, 2005). With unlearning, companies deliberately behave to change outdated and useless routines (Cegarra-Navarro, Eldridge, and Martinez-Martinez 2010; Yang, Chou, and Chiu, 2014) and to learn efficiently and effectively in a competitive environment (Becker, 2010; Hedberg, 1981; Matsuo, 2017; Nystrom and Starbuck, 1984). With unlearning, organisations are renewed in terms of technological innovations, strategies, and the development of business models (Cummings and Teng, 2003).

When the current studies on unlearning are considered, two approaches are remarkable. The first approach emphasises the elimination of outdated routines. Those who adopt this approach dispute that unlearning is the process of leaving old routines and beliefs (Cegarra-Navarro and Rodrigo-Moya, 2005; Zhao et al. al., 2013). The second approach emphasises the attention of learning/relearning. The advocates of this approach dispute that unlearning is a process where new routines, beliefs and mental patterns change old ones (Becker, 2010; Wang, Xi, Xie, and Zhao, 2017). 
Mainly, unlearning includes not only the withdrawal of old routines and beliefs but the formation of new processes such as learning/relearning (Azmi, 2008).

\subsubsection{Levels of Unlearning}

Unlearning subsists of three levels: individual, group and organisational.

Individual Unlearning: The present literature suggests that an organisation cannot unlearn by itself (Cegarra-Navarro and Sanchez-Polo, 2008) and individual unlearning is considered as the first stride in the unlearning process (Becker, 2003).

The work of Cegarra-Navarro and Rodrigo-Moya (2005) suggested that individual unlearning is break into three stages in the unlearning process, which is described as a cross-level change from the individual to the organisation: defining the problem, changing the cognitive model, and including new control measures. Individual unlearning begins with the definition of ancient knowledge and routines, in particular. When individuals define and become aware of ancient knowledge and routines, they change their cognitive structure, which leads to individual learning (Zhao et al., 2013). When individuals come across a problem, individual mental patterns and routines are intentionally shifted via unlearning to reach a solution. Changes that occur in individuals include the replacement of the previous behaviours, ideas, and actions with new ones and may create tension between the beliefs of the individual and the group's activities (Cegarra-Navarro and RodrigoMoya, 2005). This tension may only be determined by combining individual switches into the group and organisational acknowledgement. Therefore, individual beliefs and routines will become in line with organisational activities (Cegarra-Navarro and Rodrigo-Moya, 2005). Thus, individual change may trigger a bottom-up change to the top and promote organisational unlearning by creating a positive effect on the organisational change (Zhao et al., 2013).

Group Unlearning: Akgün, Lynn, and Byrne (2003) assessed group unlearning as a process of altering the beliefs, norms, values and routines of the group. CegarraNavarro and Rodrigo-Moya (2005) stated that unlearning at group level subsists of three stages: knowledge disintegration, knowledge sharing, and elimination of knowledge. Specifically, knowledge disintegration starts with individuals identifying 
out-of-date knowledge and transferring it to other members of the group. The knowledge sharing stage is the process of socialisation in which individuals share knowledge with others (Nonaka and Takeuchi, 1995). If group members have shared values, mission and vision, they will want to share ancient knowledge with others. Sharing of knowledge effectively facilitates group unlearning at the group level by transforming implicit knowledge of individuals into explicit knowledge of groups. In the phase for the elimination of knowledge, groups manage to unlearn by discarding unnecessary and outdated knowledge (Zhao et al., 2013).

Organizational Unlearning: Unlearning at the individual and group levels serve as a framework for improving the learning capabilities of companies and for improving their business performance. Since the organisational learning process involves not only the elimination of old routines and beliefs but also the establishment of new learning/relearning processes, the following three factors are essential for the specification of unlearning: the ability to alter product development procedures to modify to the new conditions; the ability to accommodate informationsharing mechanisms to adapt to the new conditions; and improvement of decisionmaking processes to adapt to the new conditions (Wang, Qi, and Zhao, 2019).

Cegarra-Navarro and Wensley (2019) also explained the interaction of the contextual components with a cycle, emphasise that there is a mutual relationship between the levels in the unlearning cycle. From these perspectives, awareness is the process in which an individual is conscious of old rules, routines, or processes in individual unlearning. Relinquishing contributes to unlearning at the group level as a process that approves people not to repeat the duplicate old failures and abandon them by revealing knowledge that has been the basis of errors that may have essentially been "hidden" in the past. Thus, failures, errors and complications may cause the change of beliefs and probably to the development of employees (Hislop, Bosley, Coombs, and Holland, 2014). At the organisational level, unlearning is associated with relearning. With relearning, old knowledge is put aside while potentially learning new things (Zhao et al., 2013). 


\subsubsection{Types of Organizational Unlearning}

Distinct coincidental settings and structures demand organisations to use the proper unlearning process. Akgün et al. (2007) classified types of unlearning with an adaptation from Gnyawali and Stewart (2003), considering it under two main categories as the rate of change in routines and as the rate of the change in beliefs. Accordingly, there are four types of unlearning: Reinventive unlearning, formative unlearning, adjustive unlearning and operative unlearning.

Reinventive unlearning describes the fundamental changes in an organisation's existing beliefs and routines. What triggers re-inventive learning, which is the heart of radical organisational change and transformation, change in the environment and unpredictability at a high level. In such an environment existing information loses functionality very rapidly. Reinventive unlearning allows organisations to perform radical changes (Starbuck, 1996) by providing strategic reorientation (Greenwood and Hinings, 1996). It is required, in particular, if an organisation competes in the next generation of products or the context of new disruptive technologies (Christensen, 1997). It is difficult, risky, and its results are uncertain.

Formative unlearning is an unlearning that occurs when more attention is established on beliefs and less emphasis placed on routines. Organisations generate new shared, standard schemas and use them to reinterpret knowledge. With this unlearning, organisations advance the ability to express a new meaning. Environmental change at the highest level, where many sources of knowledge are available, and change of knowledge occurs more predictably over time, triggers formative learning. In such an environment, companies tend to change their strategies and rearrange their staff (Akgün et al., 2007).

Adjustive unlearning elaborates more on routine changes and less on changes in beliefs. This kind of unlearning is linked with evolutionary innovation. It encourages the change and progress of new strategic business units with new product groups. It involves engineering intervention and redesign of business processes to improve the speed and quality of production. The unpredictability of 
environmental events that require adjustive learning is high, but their uncertainty is low. As knowledge changes rapidly and randomly in this type of an environment, companies shall gather knowledge about environmental events rapidly and distribute knowledge across the organisation using new media and perception units (Akgün et al., 2007; Gnyawali \& Stewart, 2003).

Operative unlearning refers to minor changes in an organisation's beliefs and routines. This type of unlearning holds a diminished separation from structural consistency. It aids to sustain the internal credibility of the organisation and includes corrections to systems, processes or structures. However, it does not include a significant change in the strategy, the core values or the corporate identity. It is possible that operational unlearning shall be required when there is a relative environmental stability present, and it is likely to continue for a long time. The environment that encourages active learning has a low level of uncertainty, and it has an unpredictable nature. A typical example of active learning is the incremental product advancement acts in organisations (Akgün et al., 2007; Gnyawali \& Stewart, 2003).

\subsubsection{Measuring and Operationalising within the Unlearning Context}

Many researchers in the literature have tried to render organisational unlearning operational and attempted to measure it. Yang, Chou, and Chiu (2014) attempted to define unlearning by measuring the changes in the strength of ties between the companies and their suppliers/customers. Sheaffer and Mano-Negrin (2003) measured unlearning with an item focusing on an organisation's asset in unlearning and two other items focusing on the organisation's drive for change. Otherwise, Cegarra-Navarro and Rodrigo-Moya (2005) advanced a different scheme to measure unlearning by adding points such as sharing of knowledge and the problem-solving capacity of employees and their managers.

Cegarra-Navarro and Wensley (2019) argue that one of the indirect ways of measuring organisational unlearning is through the explicit expression and development of measures that some researchers define as the "context of unlearning". As Azmi (2008) points out, a context that allows for unlearning may 
only be possible through an organisational structure that contains a culture which supports people to acquire new skills and knowledge consciously, as well as to create opportunities to examine and explore existing ones. Based on these considerations, Cegarra-Navarro and Wensley (2019) state that is unlearning demands the existence of three different dependent factors. Structures and processes at the individual level that allow individuals "to think outside the box" or to revise their habits by providing them the opportunity to examine the perceptual lenses used by employees. Structures and procedures at group level that simplify the adoption of new habits, structures and processes at organisational level that help for the employees to recognise and adapt to new knowledge and knowledge structures creates a context for the measurement of unlearning.

Cegarra-Navarro and Sanchez-Polo (2008) stated that the context of unlearning might be measured using three sub-dimensions. Notably, these dimensions are very similar to the contextual components of the Cegarra-Navarro and Wensley (2019) as mentioned above. The first dimension, the examination of lens fitting, which describes changing perspectives of the employees by disrupting their habits, measures individual unlearning. The dimension of the framework for changing individual habits, which includes the processes within companies that allow employees to apply and improve their problem-solving skills; and the last dimension, the framework for consolidating emergent understandings, which includes the organisational process in which employees may be liberated in practising their skills by applying new mental models, measures organisational unlearning (Cegarra-Navarro, Martinez-Martinez, Ortega Gutiérrez, and Luis Leal Rodríguez, 2013).

\subsubsection{Antecedents of Unlearning}

Factors affecting the unlearning process have attempted to be explained by different researchers in the literature (Akgün et al., 2006; Azmi, 2008; CegarraNavarro, Eldridge, and Martinez-Martinez, 2010; Sinkula, 2002). The different factors affecting the process of unlearning may be grouped under two dimensions: factors related to the external and the internal environment of the organisation. 
Factors Related to the External Environment: The significance of environmental turbulence as a precursor or trigger of unlearning is frequently emphasised in the literature of organisational change and learning (Akgün et al., 2006). According to Westenholz (1993), as the external environments in which organisations operate within change, the existing belief structures shall be restructured. Thus the learning process is affected. Sinkula (2002) also observed additional environment-oriented factors based on different unlearning elements. In the first one of these factors, the customer factor, he described that the strength of the company's ties with the customer is related to the amount and timing of the consequent unlearning. Moreover, environmental regulations issued as a result of growing customer pressure are seen as an external trigger for unlearning (Cegarra Navarro et al., 2010). Sinkula (2002) argues that other factors that affect unlearning are the changes in the intensity of competition (competition factor) and the information of the strategic partners (common factor). In order to survive in a highly competitive external environment, organisations can reshape their processes in line with their focusing or differentiating strategies. Moreover, the organisation's contact and partnership with other people, companies and industries through strategic cooperation allow the emergence of new ideas and questioning of old habits (Westenholz, 1993).

Factors Related to the Internal Environment: In addition to the factors related to the external environment, organisations may experience various internal crises within themselves. For example, Akgün et al. (2006) showed team crisis and anxiety as antecedents in their studies, in which they researched the antecedents and the results of unlearning in new product development teams. Many researchers draw attention to the existence of a crisis environment in organisations to provide learning and reinterpretation. It is also emphasised that, if necessary, senior management shall create an environment that allows employees to think by creating an artificial crisis (Herdberg, 1981).

Becker $(2008,2010)$, on the other hand, has mentioned the importance of the organisational structure, executive support, training, employee qualifications and organisational culture in order to create an unlearning environment. Concerning the 
organisational structure, Azmi (2008) mentioned structural flexibility as the distinguishing feature of the success of an organisation. Besides, agility is also essential for companies, due to business organisations having a sensitive and continually developing structure. The goal here is to anticipate opportunities to keep up with the changing environment. Steadfastness is another significant dimension of unlearning. What drives companies to success is their support for change with commitment, determination and persistence for achieving the corporate vision and goals. Also, the tactfulness of the company, particularly its capability for evaluating conditions in case of uncertainty and making prudent and cautious decisions, affects unlearning.

It is also stated that the presence of executive support as an element of the internal environment affects the unlearning process positively (Schein, 1993). Nonaka and Konno (1998) suggested that the unlearning process requires individual initiatives and effective management. Within this process, senior managers play an essential role in organisational unlearning, at the organisational level in particular (Zhao et al., 2013). It is known that the presence of new materials, processes or systems that are to be continuously learned in the organisation shall also have an effect on the replacement of what is already known, or on the start of unlearning with employees who receive continuous training. Besides, employees' willingness to learn and their openness to change as a trait of their personality is a vital component for a successful unlearning process (Becker, 2008). Regarding the effect of the organisation's employees on the learning process, Akgün et al. (2006) found that the recruitment of new people in the team/organisation positively affects the unlearning process. At this point, employees' experimentation is considered as one of the factors that positively affect the unlearning process.

Azmi (2008) emphasises that cultural characteristics are significant in the successful execution of learning, unlearning and relearning processes. He argues that cultural elements will help to create the collaborative environment required for unlearning. Lee and Sukoco (2011), on the other hand, found that unlearning is easier in organisations where the culture of justice has been established and where the perception of procedural justice is high. 


\subsubsection{Positive Consequences of Unlearning}

Organisational unlearning provides significant benefits for organisations that operate in complex environments, and that want to be renewed and want to develop themselves. The single most important benefits are that it facilitates organisational change, improves the adaptive capabilities of the company by providing organisational flexibility and contributes to the dynamic and innovative characteristics of the organisation. When the relevant literature is reviewed, it can be seen that various researchers support the positive outcomes mentioned with both empirical and conceptual studies (Akgün et al., 2007; Azmi, 2008; Becker, 2008; Wang, Lu, Zhao, Gong, and Li, 2013; Zhao et al., 2013).

Some authors emphasise that organisational unlearning has a vital role as a facilitator of organisational change (Akgün et al., 2007; Hislop et al., 2014; Martin de Holan, 2011; Tsang and Zahra, 2008). At the heart of the concept of unlearning lies the adaptation of organisational values, norms and behaviours by changing mental models, and established logical and behavioural patterns (Jiménez Jiménez et al., 2010). Martin de Holan and Phillips (2004) suggest that companies will forget specific knowledge, practices, and routines before acquiring new knowledge. Similarly, McGill and Slocum (1993) argue that the first step in learning is to challenge these ways of thinking that functioned well in the past.

Unlearning allows the formation, implementation and use of new technologies that facilitate orientation to absorptive capacity through the acquisition of internal and external knowledge and allow creation and implementation of new knowledge structures (Cegarra Navarro, Eldridge, and Wensley 2014; Cepeda-Carrion, CegarraNavarro, and Jiménez-Jiménez, 2010). In this context, it is argued that unlearning in organisations is a prerequisite or a precondition for the realisation of organisational learning (Wang, Lu, Zhao, Gong, and Li, 2013) or relearning (Azmi, 2008). Azmi (2008) states that the learning-unlearning-relearning model helps for the revival and renewal of organisations, and it accompanies various strategic initiatives such as the redesigning of business models and corporate processes, overhauling of traditional 
structures, and reorganisation of human resources. All of these initiatives are vital to the success and sustainability of the organisation (Martin de Holan, 2011).

Becker (2008) argues that organisations that aid unlearning tend to generate a surrounding suitable for new technologies and sustainable innovation. In addition to Becker (2008), there are some other studies in the literature which point out that unlearning increases innovation (Cegarro-Navarro et al. 2010; Leal-Rodriguez, PerisOrtiz, and Leal-Millán, 2017; Mieres, Sánchez, and Vijande, 2012; Rebernik and Sirec 2007; Sinkula, 2002; Wang et al. 2013). Iansiti (1995) mentions the importance of flexibility and the capability to respond quickly in order to develop new products and technologies for organisations operating in varying environmental conditions. The fact that the ability to renew information in organisations that succeed in unlearning is higher brings the company ahead of competitors in the innovation race (Leal-Rodriguez et al., 2015). Imai, Nonaka and Takeuchi (1985) also state that unlearning adds flexibility to the organisation in the new product development process. Unlearning may open up space for new knowledge in the memories of the organisations and create opportunities to look for new ideas (Zahra et al., 2011). Unlearning that allows for the elimination of group/team memory is considered as necessary for a successful product innovation performance (Akgün et al. 2007). Sinkula (2002) argues that unlearning makes it easier for market-oriented organisations to provide more excellent value for their customers, as unlearning improves organisational innovation.

\section{DESIGN OF THE RESEARCH}

\subsection{The Aim and Importance of the Research}

Routines represent a company's capability to respond to the environment. Organisational routines are described as repeated interdependent patterns of action accomplished by a large number of organisational members hold in the fulfilment of organisational tasks (Feldman and Rafaeli, 2002). However, routines may threaten the survival of an organisation as a result of the possibility of creating dependence and inertia (Swift and Hwang, 2008). With shifts in the surrounding, earlier obtained knowledge constantly comes out-of-date and fails its value. This out-of-date and 
inoperative knowledge blocks the flow of new information so that organisations become incapable of updating their knowledge over time. Notably, new external information might conflict with old information within the Company (Becker, 2010). Also, this ancient knowledge, which has long been rooted in organisations, gradually forms organisational routines and beliefs that prevent new knowledge from entering. Therefore, eliminating out-of-date knowledge, routines, and beliefs helps to obtain new external knowledge and to facilitate effective management of knowledge (Azmi, 2008).

Marin de Holan and Phillips (2004) define the context of unlearning as the context in which companies want to ignore the knowledge that creates a barrier to achieving organisational objectives. In a turbulent and dynamic environment, knowledge quickly becomes obsolete (Hedberg, 1981). This rapid ageing compels companies to renew this knowledge periodically. This renewal is unlearning, and one of the main weaknesses of many companies is that they are not fully capable of unlearning (Leal-Rodriguez, Eldridge, Roldán, Leal-Millán, and Ortega-Gutiérrez, 2015). In this context, it is essential for a company-oriented at research and development, and that attaches importance to innovation to have the ability to unlearn, as they will have a more flexible structure and shall respond to environmental challenges faster and better than their competitors (Damanpour and Gopalakrishnan, 1998).

In this context, this research aims to analyse the process of unlearning in an innovative company with a high capability of $R \& D$, to determine the unlearning and its antecedents affecting the unlearning process, to find the positive outcomes of unlearning for the company and establishing a model as a result of these findings. Turkey, the country where this research was conducted, aims to achieve economic growth with goods and services that create added value by using advanced technology. The company taken as the subject of the research is an advanced technology company that produces projects in defence, energy and environment sectors, that acts as a solution partner for its customers and aims to maintain its existence with innovative products. Therefore, the firm analysed in this research is vital for the practitioners in terms of field of activity and the findings obtained. In 
this context, it is thought that the results obtained from this research shall contribute to the literature on learning and unlearning.

\subsection{Methodology}

It is noteworthy that the numbers of qualitative and quantitative research articles are limited when the literature on unlearning is reviewed. In the literature, it is emphasised that there is a need for case studies that examine the processes of unlearning, deepening the antecedents, revealing the type of unlearning and emphasising the positive outcomes of unlearning for the Company (Akgün et al., 2007). In this study, an exploratory case study amongst the qualitative research methods was used to identify the unlearning processes, antecedents of the unlearning and positive outcomes of unlearning for the company.

The data related to the research were collected from the specified company by conducting interviews between 10-11 June 2019 so an ethics committee permission document is not required because the data collection time is before 1 January 2020. The semi-structured interview technique was used as the data collection method for this study. This method is neither as rigid as fully structured interviews nor as flexible as unstructured interviews; it is placed between the two extremes (Karasar, 1995: 165). Before preparing the questions for the interview, a national and international literature review was conducted on the subject of the research. After designing the subject, the items and questions that were thought to be included in the form were determined. During the interview, questions about the company, questions to determine the type of unlearning, questions about the antecedents and positive outcomes of unlearning and questions for determining the perspectives of the participants were included.

Two senior managers, one company owner, and five randomly selected workers were interviewed throughout the company. Two researchers conducted the interview. During the interview, information about the research was provided, and the concept of unlearning was defined first. A recorder was used to prevent loss of data during the interviews. The participants were informed that a recording device would be used in the interviews and that the records could be listened to by the 
participants at the end of the interviews and if necessary, that the views in the records could be partially or entirely removed as per the desire of the participants. Thus, the researchers tried to prevent any adverse effects that may be caused by the presence of a recorder on the participants. After the interview, the company official COO (Chief Operating Officer) introduced the whole company and the processes, provided information by giving a tour of the company, and shared documents about the company that do not carry trade secrets but provided information about the processes. In this context, in addition to the semi-structured interview technique, document analysis and observation techniques were also used to acquire data.

In the process of data analysis, descriptive and systematic analysis methods were used. Descriptive analysis is a type of qualitative data analysis that includes summarising and interpretation of data obtained with various data collection techniques according to predetermined themes. In this type of analysis, the researcher may frequently include direct quotations in order to reflect the views of the individuals interviewed or observed (Yıldırım and Şimşek, 2003). The four stages of descriptive analysis, namely establishing a framework, data processing, defining and interpreting of the findings, were followed (Altunışık, Coşkun, and Bayraktaroğlu, 2010). Firstly, a full voice transcription of the data obtained from the interview was performed. Then, narratives were read in order to outline and define the elements of the thematic areas, and they were categorised to form a framework for descriptive analysis, based on the conceptual framework of the research, interviews and observations. The categorisation was undertaken by considering the external and internal factors affecting the unlearning as described in the literature. Business environment and strategic alliances of the company amongst the factors related with the external environment; and organisational structure, executive support, employee characteristics and organisational culture were amongst the factors related with internal environment subsequently determined as the dimensions of categorisation. According to this thematic framework created, the data was processed, and the findings were defined. After the interpretation of the findings by the researchers, narratives were sent to the concerned parties via e-mail for 
approval. Finally, the analysis units defined among all narratives were grouped and analysed according to each category size.

The company owner did not allow the use of the company's name or the names of its managers. In the following sections, the company subject to the study is referred to as company $\mathrm{A}$, and the owner of the company is referred to as $\mathrm{Mr} \mathrm{E}$.

\subsection{About the Company}

Company A was established by two brothers as a Design \& R\&D company with 100\% domestic capital in 2008 in Istanbul with the aim of research, development and design. As of 2012, it continues its export-oriented activities in the Antalya Business Park. The products obtained in the ongoing and delivered projects are actively exported to approximately 40 countries. A few years ago, the company became the leading service exporter. It exports $R \& D$ projects to countries including America and Japan by cooperating with universities and through its consultancy services. Furthermore, it is ranked within the top 20 fastest growing R\&D companies in Turkey. In the projects carried out with domestic and foreign customers, the company addresses the required products or systems at a basic level and serves at all stages from the hardware design to embedded software and from mass production processes to technical support. The company operates in 4 main areas: embedded software, electronic design, mass production solutions, R\&D and innovation. The company provides services in areas such as embedded system software, testing and troubleshooting equipment, motor drives, linear motor design, magnetic design and finite element analysis.

Company A's mission is as follows:

"To meet the expectations of its employees and customers at the highest level, while serving the country's economy with its designs, applications and support services. Our current goals are to contribute to Turkey's economy by developing projects that shall improve Turkey's technology in defence, environment and energy sectors". 
Company A's vision is as follows:

"Always take its place in the dynamics of the developing world, carrying the flag of leadership in innovation, and that always remains young and dynamic."

Company A can respond to multidisciplinary projects with top, middle and lower-level managers with university degrees specialised in different fields such as Electrical, Electronics, Mechanical, Mechatronics, Industrial Engineering, and Industrial Product Design, and also with its blue-collar workers graduated from vocational high schools or colleges in the relevant fields. Within this context, the company employs about 150 persons. Thirty-six of these employees are in middle and upper management levels, and the rest are employed in lower levels and operations. $48 \%$ of the employees are women, and $52 \%$ are men. The rate of women employed in the business is above the average rate of Turkey.

Company A has Quality, Production, Sales, R\&D, Human Resources, Purchasing, Logistics and Customs Clearance, Accounting and Finance Departments. Twenty-two employees are employed in the R\&D department; and this figure, too, is above the industry average in Turkey. The company expresses the following regarding its $R \& D$ activities:

“Our Company focuses its R\&D activities on Electronic Products and Mechatronic Systems. Our prioritised areas of specialisation are actuator systems and drives, where there is a great shortage of domestic products for the manufacturing industry, and other examples of embedded systems. We are conducting our R\&D studies in cooperation with national and international universities in order to create innovative technologies and obtain products with high added value. We publish our studies in prestigious international journals with our academic titles. Moreover, we help our customers to bring their innovative characteristics forward and to achieve products and solutions with high added value".

\section{FINDINGS}

The findings obtained from the interviews with the owner, managers and employees of Company A, and the observations and reviews of the documents were 
analysed considering the following unlearning cycle. Figure 1 states this cycle, and in the subtitles, this cycle is tried to explain.

Antecedents of Unlearning

- Factors Related to the External Environment

- Business Environment

- Strategic Cooperation

- Factors Related to the Internal Environment

- Elements of Organizational Structure

- Executive Support and Leadership

- Organizational Culture

- Employee Characteristics

Figure 1. Unlearning Cycle of Company

Source: Created by the authors

\subsection{Antecedents of Unlearning in Company A}

\subsubsection{Factors Related to the External Environment}

Business Environment: The owner and top-level managers of Company A describe the business environment in which they operate as variable and turbulent. They state that their sector has a dynamic structure as their fields of activity are advanced technology. Moreover, they emphasise that environmental uncertainty and unpredictability occurs not only for Turkey but for countries which they carry out joint projects with, such as the USA. However, they do not complain about this dynamism and uncertainty. They consider the crises and problems arising from both the remote environment and the immediate business environment as a way to improve them. They state that the factors that drive the company to change are supplied from two primary sources. The first of these is the new ideas and projects, and the second one is the operations performed to render quality and production processes sustainable in order to get ahead of both domestic and foreign competitors in a growing market.

Strategic Cooperation: Company A conducts its research and studies, both internally and in cooperation with its customers and suppliers. The COO summarises the company's main activities as follows: 
“We transform an idea into a project, a project into a design and a design into production. In this process, the feedback of our customers, suppliers and project partners is critical and valuable for us."

Company A states that they are currently in partnership for two long-term projects. One of these projects started with an American company as an R\&D project, and today it has turned into production. Company $\mathrm{A}$ is currently the leading supplier of this American Company. It is stated that this cooperation, which is realised as the production of an electronic board, is performed by using advanced technology that is unique throughout the world and has high-quality standards. Another project partner of Company A is from Japan. This cooperative relationship has been continuing for ten years, was started as a project partnership, and then a joint venture was established.

The company states that it does not have a large number of suppliers, but that they collaborate with their existing suppliers, mutually contributing to each other in their innovation and process improvement activities. The $\mathrm{COO}$ explains this with the following example:

"In the project with our American partner, we saved much time thanks to our supplier's recommendation. We reduced the work to a 3-month period where it was only possible for our competitors to complete in 11 months, and we produced a solution."

It is stated that customers and suppliers are also considered as the solution partners of the company, and feedback contributes significantly to the improvements in product quality or processes. Both managers and employees state that they are in constant contact and regularly interact with their suppliers and customers both at the project stage and the production stage and that they carry out an interactive process. This interaction leads to long-term working relationships with customers. The company also conducts design and project works in cooperation with universities both in Turkey and abroad. 


\subsubsection{Factors Related to the Internal Environment}

Elements of Organisational Structure: Achieving organisational success requires questioning old ways of thinking and doing business. As Company $\mathrm{A}$ attaches importance to innovation and continuous improvement, they continuously strive to redesign their systems, processes and tools and achieve more significant results. Since company A has a project-based organisational structure, they attach great importance to cross-functional teams. Teams are used in production and R\&D departments. Every person in the business reports any error that they notice or anticipate. For example, a blue-collar employee reports problems to the unit supervisor or the foreman. The unit supervisor or foreman reports the issue to the relevant unit. The relevant unit tries to solve the issue by applying the required action plan. All problems are recorded within the business to ensure that the same error is not repeated.

Every week, unit officers meet and review the successes and failures that have occurred during that week. The resolution achieved is shared by each unit with its employees. Key performance indicators are also given importance in the production units, and it is stated that lean production and management tools are integrated into the system. It is also thought that Kaizen groups are beneficial in terms of doing their jobs better and more efficiently. When all these structural characteristics are evaluated, it may be stated that double-cycle learning takes place in the firm.

The COO of the Company states that their structural characteristics provide them with a very competitive edge and that their competitors are far behind Company $\mathrm{A}$ in terms of quality and number of production units and gives the following example:

“We are currently the main supplier of the largest elevator door manufacturer in Europe. This Company exports to 73 countries. The former main supplier was one of the largest and most innovative companies in the world. However, they have withdrawn from the market and stopped competing with us, because they could not compete in terms of the features of our product and the price we offer to the customer." 
Executive Support and Leadership: Company A was established by two brothers in 2008 with 100\% domestic capital. One brother is a mechanical engineer, and the other is a mechatronics engineer. The business is a 1st generation family business, but they have internalised the need to institutionalise from the first day. 98\% of the businesses in Turkey are family businesses, but the ratio of the companies that consider institutionalisation as a necessity is relatively low. In this context, it can be observed that the founders of the company examined the successes and failures of other family businesses, and took lessons from them, and attach importance to professional employees and support the emergence of different perspectives by empowering their employees in the following statement of the owner of the Company, Mr E.:

"When we consider the profile in Turkey, almost none of the companies can reach fourth or 5th generation, if we exclude one or two of our major holdings. We do not want to be like this, our goal is to ensure sustainability, so institutionalisation and professional managers are important for us. We offer the right to take the initiative and attach importance to autonomy. I do not say "I know this" in case of an issue, we manage mutually. Different perspectives are essential; everyone decides in their field of expertise."

Employees and professional executives also state that $\mathrm{A}$ is a company with rapidly growing goals which has internalised institutionalisation. At this point, it is emphasised that managers are people-oriented, and their most essential characteristics are specified as being visionary and devoted. The perceived support level of the employees was observed to be relatively high.

Organizational Culture: The managers and employees interviewed in Company A consistently emphasised the concepts of trust, respect and commitment while defining their corporate culture. The managers stated that they are focused on establishing a people-oriented organisational culture, that they are a company that values their employees and that they try to create a work environment in which the employees feel this. For example, company owner Mr E. states the following: 
“The same conditions apply to my employees if there is an environment that I will not be involved myself, that I would feel uncomfortable or unwilling. For example, I will never serve a meal that I will not eat myself to my employees. Our goal is to make every employee here happy, and this provides a commitment and makes us open to improvement."

The owners of the business and the top-level managers have stated that they keep all formal and informal communication channels open. They stated that each employee in the business contributes to the common goals and that they are aware of this and that each employee is happy to be a part of the process. The open communication is observed in the interviews with the employees and observations made in the business environment. It could be argued that Company A has effective communication within the company and a trust-oriented sharing culture.

Employee Characteristics and Human Resources Policies: The human resources management team in Company $\mathrm{A}$ is a coordinated team that works with the other departments in the company. The employee turnover rate is meagre. Having a low turnover rate is considered to be closely related to both human resources policies and the organisational culture mentioned above.

The recruitment policy of Company A is: transferring more experienced managers to more senior positions and recruitment of new graduates for lower tiers and blue collars. For example, the Operations Manager (COO) joined the Company 9 months ago, who has worked in automotive and technology companies and has extensive knowledge and know-how experience. Similarly, the R\&D manager was transferred from a company five months ago, which is good at in the field of technology in Turkey. The Quality Manager has also been transferred to the Company three months ago from a relatively well-established automotive company operating in Turkey. The owner of the Company, Mr E., stated that these transfers improve the unlearning ability of the company and that this very important for them, and provided the following example:

"It has been one or two weeks since our quality manager started in the company. We had measured cable lengths manually with some ruler that is called a 
calliper. He proposed to do this with a new apparatus. This situation never caught our attention, although it is a straightforward thing, sometimes the company may be blind as a whole. He immediately e-mailed the details of the part to the $R \& D$ department. Within 1 hour, the R\&D department designed the part in 3D, and we printed it out and started using it. Using this apparatus reduced the time required for the measurement process and made it possible to measure with $0 \%$ error. Such improvements also improve our deadlines, as cycle times are close to each other in the process flow."

The reason for preferring new graduates for lower-tier management and bluecollar positions in the company is explained by the fact that it is considered to be more beneficial in terms of adoption of organisational culture and business discipline. The characteristics that are generally paid attention to during the recruitment process and sought in all employees are enthusiasm for learning, openness to change, being keen on research, being curious, like working and having responsibility. In the recruitment meetings and interviews, it is tested whether the applicants have these characteristics. The suitability of an applicant to a position is decided respectively by the HR manager, then the department manager and finally by the owners of the company as per the position.

Flexible working hours are applied to the company. The perspective of Company $\mathrm{A}$ is to consider what the employee adds to the company and how efficient he/she is. Therefore, employees are rewarded. Rewards are awarded as a bonus, salary bonus or in-kind. Mr E., explains that all employees in the company know and are entirely sure that they will get a share when the company achieves.

"When we moved to the Free Trade Zone, we gained some financial advantages and shared these advantages with our employees. As a result of the agreement with the bank for salary payment, we paid the entire promotion to our employees."

Moreover, the human resources department organises several activities to ensure socialisation within the company. For example, brunches are organised periodically with the participation of employees and their families. Competitions that 
require creativity and solidarity are organised to improve teamwork and team awareness. By organising various sports activities, the aim is to ensure that employees have both fun and interaction.

\subsection{The Unlearning Type of Company A}

Company $\mathrm{A}$ is focused on research and development, and that can adapt advanced technology to its systems. The company provides integrated solution proposals to its customers and other stakeholders with its high capacity for innovation. As mentioned in the literature, if a company competes with new generation products and advanced technology, it will require re-inventive unlearning. In view of the characteristics of the company it can be said that its unlearning type is re-inventive. The so-called new generation or third generation approach is a more agile product development system that can handle the frequent repetition of multiple design options at the beginning of the process, based on continuous testing and highly sophisticated customer-oriented design changes. This method, which promotes flexibility and tolerates the unpredictability of the first stages of product development, reduces uncertainty by ensuring that the second part of the cycle is to be introduced to the market with less cost and less delay (Jaruzelski, Holman, and Daud, 2011). Also, it is stated that the environment in which the company operates as turbulent and uncertain. These properties are consistent with the characteristics of the type of work environment, which makes re-inventive unlearning more meaningful than other types of unlearnig.

\subsection{Outcomes of Unlearning}

Officials of Company A state that the contribution of unlearning at the individual, group and organisational levels as very important. According to the statements of the $\mathrm{COO}$, the most important contribution of organisational unlearning for the company is the achievement of the capability to act quicker and with more flexibly with the improvement of quality:

"The acquired experience is significant to us. We carry out continuous improvement activities in our operational processes and apply lean manufacturing and management tools. Furthermore, we reap the fruits of this. In 2018, over 800,000 
products were dispatched, and only one error occurred. It is a significant achievement for our industry".

All these elements reflect as an increase in productivity for the company. Flexibility, speed and innovative solutions increase customer satisfaction and perception of value. Moreover, this allows customer retention for a more extended period. In addition to this, trust-oriented and collaborative innovation projects carried out with customers and suppliers enable the company to increase capacity and grow.
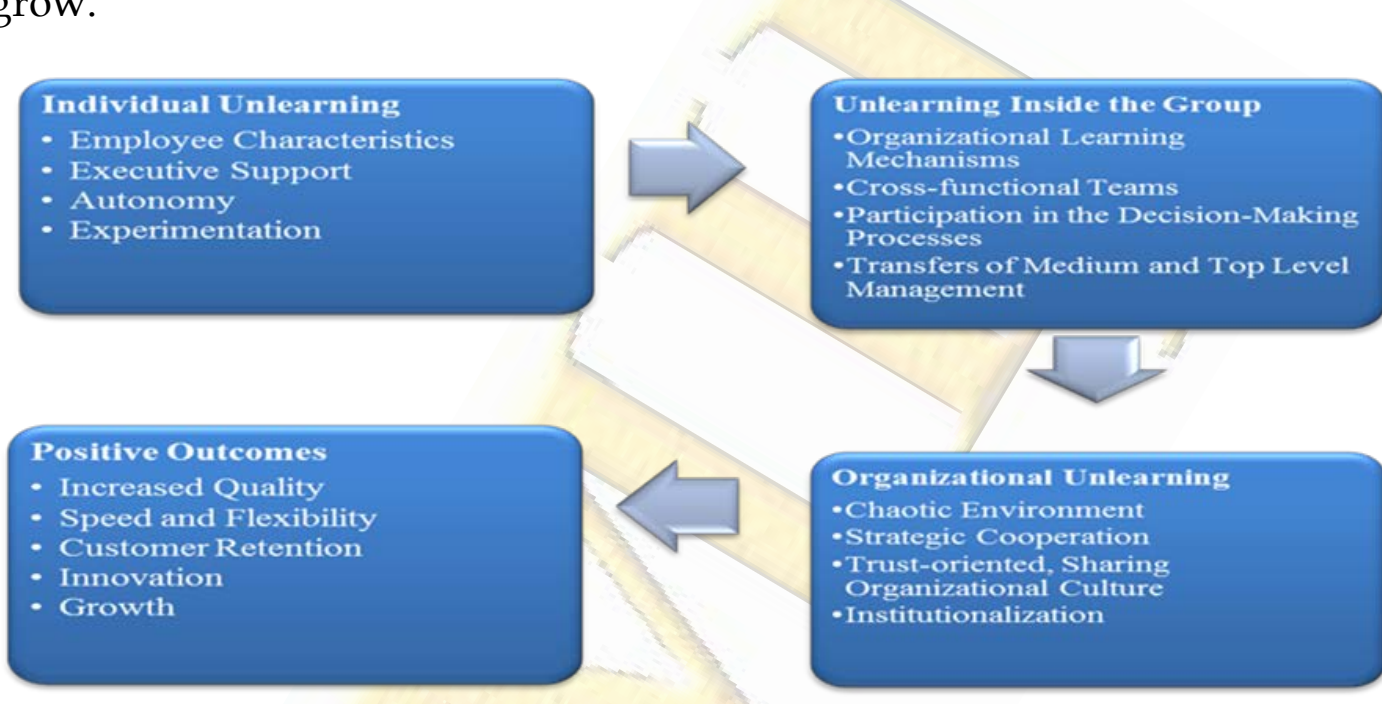

\section{Organizational Unlearning \\ - Chaotic Environment \\ - Strategic Cooperation \\ - Trust-oriented, Sharing \\ Organizational Culture \\ - Institutionalization}

Figure 2. Conceptual model of the research

Source: Created by the authors

The elements considered as antecedents of unlearning for Company A are classified according to their levels of unlearning in Figure 2. As a result of the evaluation of the obtained data, the antecedents that affect individual unlearning may be specified as the characteristics of the employees; the presence of the perception of organisational support; allowance of high levels of error tolerance through trials providing autonomy to the employees. It may be argued that the factors facilitating unlearning at the group level are the availability of mechanisms (structures and processes) that allow organisational unlearning; cross-functional teamwork; participation of employees at all levels in decision-making processes; and the transfers of the managers. Furthermore, it may be argued that organisational unlearning is affected by the chaotic business environment, strategic alliances, 
organisational culture and awareness for the need for institutionalisation and the efforts for this purpose. All of these antecedents enable the company to acquire some positive outcomes, as mentioned earlier.

\section{CONCLUDING REMARKS}

When a general evaluation of the findings of the research findings is made, it is observed that company A can unlearn and the processes related to unlearning. When the findings obtained in terms of the unlearning process and its subdimensions are combined, it is noteworthy that the company sees unlearning at the centre of development and improvement. Based on the results of the research, it may be said that the elements of the model presented in Figure II. are mostly in line with the findings and proposals in the unlearning literature.

Azmi (2008) states that unlearning occurs within the learning/unlearning/relearning cycle. When the process in Company A was observed, it was noted that this cycle was actively used. The company adopted a learning-oriented approach for all employees from the lowest level to the highest level and provided an environment that allows employees to transfer their experiences by implementing the organisational learning mechanisms. The company also developed the ability to become aware of outdated routines, processes and systems at the individual, group and organisational levels, and thus it enables rapid adaptation to new knowledge, habits and processes within the company. Similarly, Casillas, Acedo, and Barbero, (2010) and Rodrigues and Souza Bido (2019) indicate that unlearning facilitates relearning in organisations.

The findings obtained from the research are discussed in three sub-unlearning levels as per the model of the research, as indicated in the summary of the literature section. Company A's overall effort for individual unlearning is primarily the provision of autonomy to its employees. Nonaka and Konno (1998) and Rodrigues and Souza Bido (2019) state that the process for the elimination of routines requires individual initiative and autonomy. The fact that employees may easily take the initiative and not hesitate to try is closely related to the perception of executive support in Company A. The tolerance shown to errors encourages employees to be 
innovative and open to change (Nystrom and Starbuck 1984; Rodrigues and Souza Bido, 2019). Employees of organisations that can unlearn may control the organisational memory without blindly attaching their capability for adaptation to changing conditions to it by renewing any ancient knowledge stored in their organisational memory (Mezias, Grinyer and Guth, 2001). The human resources department also plays an active role in providing individual unlearning in Company A. A series of activities and pieces of training to improve social interaction are planned to enable individuals to share and integrate their explicit and implicit knowledge with others. Employee happiness and being people-oriented are essential values for Company A, as has been observed. It is emphasised that this is also important for unlearning (Rodrigues and Souza Bido, 2019).

Company A transfers top and middle-level managers first, in order to render the unlearning mechanism functional at the group level. Transfers, by allowing the joining of the competent and talented people in the field to the company, help for the transfer of the know-how experience to the company as well as for the elimination of the manager blindness, and thus for the realisation of the change and innovation in this way. Nystrom and Starbuck (1984) also stated that it would be beneficial to replace the top-level managers to provide unlearning. In order to provide unlearning at the group level, Company $\mathrm{A}$ conducts its activities in production and $\mathrm{R} \& \mathrm{D}$ departments in teams. Moreover, the cross-functional teams, which are established on a project basis within the business, lead to the emergence of new ideas and routines, particularly when combined with Kaizen circles. It is observed that the elements of the organisational learning process such as finding and correction of the errors, preparation of action plans and elimination of the repetition of the same error have become established in Company A. The fact that the organisational learning process is adopted also facilitates unlearning at the group level. Brook, Pedler, Abbott, and Burgoyne, 2016) confirmed that unlearning may make it easier to understand problems and to find solutions. Thus, it shall be possible to redesign organisational processes and systems. Azmi (2008) also emphasises that organisational processes shall be more effective, and therefore organisations shall essentially change traditional methods, tools, techniques and practices. 
When the literature is reviewed on unlearning, the frequent emphasis placed on a business environment that is uncertain and with low-level predictability triggers organisational unlearning (Akgün et al., 2006; Klammer, and Gueldenberg, 2019) can be observed. According to McKeown (2012), companies will take a conscious and proactive attitude towards unlearning in very turbulent environments. The firm defines its business environment as chaotic and dynamic and states that there is no possibility of resisting change. Karabal (2018) have also found a negative relationship between unlearning and the resistance to change in his research on unlearning conducted on the construction industry in Turkey.

The company, which was examined in the research, is a family business in its nature. The awareness of and effort for institutionalisation are also essential factors for organisational learning and unlearning processes. A family business that has not succeeded in institutionalisation may face serious problems both in terms of the employment of professional managers at upper levels and in the context of decisionmaking processes and elimination of traditional routines. Therefore, the awareness of and effort for institutionalisation, particularly within the framework of family businesses, may be added as an antecedent for organisational unlearning. The findings of the study of Leal-Rodríguez et al. (2017) also show that family businesses and organisational learning together improve the capacity of the companies to learn, develop new knowledge, innovate, and adapt to changes in the market and the environment.

The literature states that organisational culture is a critical element in the success of learning/unlearning and relearning processes (Azmi, 2008). Company A is attempting to build a trust-oriented and sharing organisational culture. The collaborative approach proposed in the conceptual model of research, for unlearning at the organisational level, implies that Company $\mathrm{A}$ is in mutual communication and cooperation with its stakeholders. Company A can renew its processes and products with the feedback it receives from its customers and suppliers. Moreover, the company conducts interactive, collaborative and innovative activities with other companies, subsidiaries and universities that are partners with them in various projects. Similarly, Nystrom and Starbuck (1984) suggested that communicating with 
different teams, organisations, and people may have an impact on the unlearning process.

Effective and efficient functioning of the unlearning mechanism provides many positive outcomes for the organisation. Organisational unlearning companies require firms to update their existing routines and thereby increase the flexibility of their resources (Wang et al., 2017). Cegarra-Navarro et al. (2014) demonstrate that unlearning may increase the capacity of organisation for absorption and the implementation of external knowledge. The officers of the company A stated that organisational learning primarily adds speed and flexibility to the company and increases the efficiency of processes. Furthermore, all this has made it easier for the company to offer alternative solutions; and provide positive outcomes such as customer retention and growth by allowing the company to develop their skills in terms of solution partnership, innovation and research and development.

It is frequently emphasised in the literature that there is a very little empirical study of how the unlearning mechanism works, despite the importance attached to the concept of unlearning (Hislop et al., 2014; Tsang, 2017). This research has the limitations of being conducted only in one company operating in a given period, in a specific country and a specific sector. With these limitations, the study is expected to contribute to the relevant literature and the business world by revealing the antecedents and management practices that affect the organisational unlearning process and its sub-dimensions. 


\section{REFERENCES}

Akgün, A. E., Byrne, J. C., Lynn, G. S., \& Keskin, H. (2007). New product development in turbulent environments: Impact of improvisation and unlearning on new product performance. Journal of Engineering and Technology Management, 24(3), 203-230.

Akgün, A. E., Lynn, G. S., \& Byrne, J. C. (2003). Organizational learning: A socio-cognitive framework. Human Relations, 56(7), 839-868.

Akgün, A. E., Lynn, G. S., \& Byrne, J. C. (2006). Antecedents and consequences of unlearning in new product development teams. Journal of Product Innovation Management, 23(1), 73-88.

Altunışık, R., Coşkun, R., \& Bayraktaroğlu, S. (2010). Sosyal bilimlerde araştırma yöntemleri. Sakarya: Sakarya Yayıncilık.

Azmi, F. T. (2008). Mapping the learn-unlearn-relearn model: Imperatives for strategic management. European Business Review, 20(3), 240-259.

Becker, K. (2008). Unlearning as a driver of sustainable change and innovation: Three Australian case studies. International Journal of Technology Management, 42(1-2), 89-106.

Becker, K. (2010). Facilitating unlearning during implementation of new technology. Journal of Organizational Change Management, 23(3), 251-268.

Becker, K. L. (2003). Managing change in regionally-based organisations-understanding the need for individual and organisational unlearning, in Proceedings Australia and New Zealand Academy of Management. Fremantle, Australia.

Brook, C., Pedler, M., Abbott, C., \& Burgoyne, J. (2016). On stopping doing those things that are not getting us to where we want to be: Unlearning, wicked problems and critical action learning. Human Relations, 69(2), 369-389.

Casillas, J. C., Acedo, F. J., \& Barbero, J. L. (2010). Learning, unlearning and internationalisation: Evidence from the pre-export phase. International Journal of Information Management, 30(2), 162-173.

Cegarra-Navarro, J. G., \& Rodrigo-Moya, B. R. (2005). Business performance management and unlearning process. Knowledge and Process Management, 12(3), 161-170.

Cegarra-Navarro, J. G., \& Sánchez-Polo, M. T. (2008). Linking the individual forgetting context with customer capital from a seller's perspective. Journal of the Operational Research Society, 59(12), 1614-1623.

Cegarra-Navarro, J. G., \& Wensley, A. (2019). Promoting intentional unlearning through an unlearning cycle. Journal of Organizational Change Management, 32(1), 67-79.

Cegarra-Navarro, J. G., Eldridge, S., \& Martinez-Martinez, A. (2010). Managing environmental knowledge through unlearning in Spanish hospitality companies. Journal of Environmental Psychology, 30(2), 249-257.

Cegarra-Navarro, J. G., Eldridge, S., \& Sánchez, A. L. G. (2012). How an unlearning context can help managers overcome the negative effects of counter-knowledge. Journal of Management $\mathcal{E}$ Organization, 18(2), 231-246.

Cegarra-Navarro, J. G., Eldridge, S., \& Wensley, A. K. (2014). Counter-knowledge and realised absorptive capacity. European Management Journal, 32(2), 165-176.

Cegarra-Navarro, J. G., Martinez-Martinez, A., Ortega Gutiérrez, J., \& Luis Leal Rodríguez, A. (2013). Environmental knowledge, unlearning, and performance in hospitality companies. Management Decision, 51(2), 341-360.

Cepeda-Carrion, G., Cegarra-Navarro, J. G., \& Jiménez-Jiménez, D. (2010). Analyzing an absorptive capacity: unlearning context and information sistem capabilities as catalysts for innovativeness. Documentos De Trabajo FUNCAS, 550, 1-31.

Christensen, C. M. (1997). The innovator's dilemma. USA: Harvard Business School Press. 
Cummings, J. L., \& Teng, B. S. (2003). Transferring R\&D knowledge: The key factors affecting knowledge transfer success. Journal of Engineering and Technology Management, 20( 1-2), 39-68.

Damanpour, F., \& Gopalakrishnan, S. (1998). Theories of organizational structure and innovation adoption: the role of environmental change. Journal of Engineering and Technology Management, 15(1), 124.

Feldman, M. S., \& Rafaeli, A. (2002). Organisational routines as sources of connections and understandings. Journal of Management Studies, 39(3), 309-331.

Gnyawali, D. R., \& Stewart, A. C. (2003). A contingency perspective on organizational learning: integrating environmental context, organizational learning processes, and types of learning. Management Learning, 34(1), 63-89.

Greenwood, R., \& Hinings, C. R. (1996). Understanding radical organizational change: Bringing together the old and the new institutionalism. Academy of Management Review, 21(4), 1022-1054.

Hedberg, B. (1981). How organizations learn and unlearn. P. Nystrom \& W. H. Starbuck (Eds.), in Handbook of organizational design (3-27). London: Cambridge University Press.

Hislop, D., Bosley, S., Coombs, C. R., \& Holland, J. (2014). The process of individual unlearning: A neglected topic in an under-researched field. Management Learning, 45(5), 540-560.

Iansiti, M. (1995). Shooting the rapids: Managing product development in turbulent environments. California Management Review, 38(1), 37-58.

Imai, K., Nonaka, I., \& Takeuchi, H. (1985). Managing the new product development game. K.B. Clark, R.H. Hayes \& C. Lorenz (Eds.), in The uneasy alliance: managing the productivity-technology dilemma (337381). Boston: Harvard Business School Press.

Jaruzelski, B., Holman, R., \& Daud, O. (2011). Next-generation product development. Tech $\mathcal{E}$ Innovation, https://www.strategy-business.com/article/00076?gko=6403c (Accessed 30 May 2019).

Jiménez Jiménez, D., Cepeda-Carrion, G., \& Cegarra Navarro, J. G. (2010). Linking unlearning with innovation through organizational memory and technology. Electronic Journal of Knowledge Management, 8(1), 1-10.

Karabal, C. (2018). Değişime direnç, örgütsel hafiza ve vazgeçme arasindaki ilişkiler. Mersin Üniversitesi Sosyal Bilimler Enstitüsü Dergisi, 1(2), 6-24.

Karasar, N. (1995). Bilimsel araştırma yöntemi, kavramlar, ilkeler. Ankara: 3A Araştırma Eğitim Danışmanlık Ltd.

Klammer, A., \& Gueldenberg, S. (2019). Unlearning and forgetting in organizations: A systematic review of literature. Journal of Knowledge Management, 23(5), 860-888.

Leal-Rodríguez, A. L., Eldridge, S., Roldán, J. L., Leal-Millán, A. G., \& Ortega-Gutiérrez, J. (2015). Organizational unlearning, innovation outcomes, and performance: The moderating effect of firm size. Journal of Business Research, 68(4), 803-809.

Leal-Rodríguez, A., Peris-Ortiz, M., \& Leal-Millán, A. (2017). Fostering entrepreneurship by linking organizational unlearning and innovation: The moderating role of family business. Management International/International Management/Gestión Internacional, 21(2), 86-94.

Lee, L. T. S., \& Sukoco, B. M. (2011). Reflexivity, stress, and unlearning in the new product development team: The moderating effect of procedural justice. RED Management, 41(4), 410-423.

Martin de Holan, P. (2011). Organisational forgetting, unlearning, and memory systems. Journal of Management Inquiry, 20(3), 302-304.

Martin De Holan, P., \& Phillips, N. (2004). Remembrance of things past? The dynamics of organisational forgetting. Management Science, 50(11), 1603-1613.

Matsuo, M. (2017). Managers' exploration activities and individual unlearning: The mediating role of learning orientation and reflection. The International Journal of Human Resource Management, 31(5), 638656. 
McGill, M. E., \& Slocum Jr, J. W. (1993). Unlearning the organisation. Organizational Dynamics, 22(2), 67-79.

McKeown, I. (2012). Teaching old dogs new tricks: why unlearning matters in SMEs. The International Journal of Entrepreneurship and Innovation, 13(1), 25-34.

Mehrizi, M. H. R., \& Lashkarbolouki, M. (2016). Unlearning troubled business models: From realization to marginalization. Long Range Planning, 49(3), 298-323.

Mezias, J., Grinyer, P., \& Guth, W. D. (2001). Changing collective cognition: A process model for strategic change. Long Range Planning, 34(1), 71-95.

Mieres, C. G., Sánchez, J. Á. L., \& Vijande, M. L. S. (2012). Internal marketing, innovation and performance in business services firms: The role of organizational unlearning. International Journal of Management, 29(4), 403-421.

Nonaka, I., \& Konno, N. (1998). The concept of "Ba": Building a foundation for knowledge creation. California Management Review, 40(3), 40-54.

Nonaka, I., \& Takeuchi, H. (1995). The knowledge-creating company: How Japanese companies create the dynamics of innovation. Oxford: Oxford University Press.

Nystrom, P. C., \& Starbuck, W. H. (1984). Managing beliefs in organizations. The Journal of Applied Behavioral Science, 20(3), 277-287.

Rebernik, M., \& Sirec, K. (2007). Fostering innovation by unlearning tacit knowledge. Kybernetes, Vol. 36(3/4), 406-419.

Rodrigues, H. G., \& de Souza Bido, D. (2019). Individual unlearning from the point of view of managers in merger and acquisition events in Brazil. Cuadernos de Administración, 35(64), 3-19.

Schein, E. H. (1993). On dialogue, culture, and organizational learning. Organizational Dynamics, 22(2), 40-51.

Sheaffer, Z., \& Mano-Negrin, R. (2003). Executives' orientations as indicators of crisis management policies and practices. Journal of Management Studies, 40(2), 573-606.

Sinkula, J. M. (2002). Market-based success, organizational routines, and unlearning. Journal of Business $\mathcal{E}$ Industrial Marketing, 17(4), 253-269.

Snihur, Y. (2018). Responding to business model innovation: Organizational unlearning and firm failure. The Learning Organization, 25(3), 190-198.

Starbuck, W. H. (1996). Unlearning ineffective or obsolete technologies. International Journal of Technology Management, 11, 725-737.

Swift, P. E., \& Hwang, A. (2008). Learning, dynamic capabilities and operating routines: A consumer package goods company. The Learning Organization, 15(1), 75-95.

Tsang, E. W. (2017). How the concept of organizational unlearning contributes to studies of learning organizations: a personal reflection. The Learning Organization, 24 (1), 39-48.

Tsang, E. W., \& Zahra, S. A. (2008). Organizational unlearning. Human Relations, 61(10), 1435-1462.

Wang, X., Qi, Y., \& Zhao, Y. (2019). Individual unlearning, organizational unlearning and strategic flexibility: The down-up change perspective. Baltic Journal of Management, 14 (1), 2-18.

Wang, X., Xi, Y., Xie, J., \& Zhao, Y. (2017). Organisational unlearning and knowledge transfer in crossborder M\&A: The roles of routine and knowledge compatibility. Journal of Knowledge Management, 21(6), 1580-1595.

Wang, X., Lu, Y., Zhao, Y., Gong, S., \& Li, B. (2013). Organisational unlearning, organisational flexibility and innovation capability: An empirical study of SMEs in China. International Journal of Technology Management, 61(2), 132-155.

Westenholz, A. (1993). Paradoxical thinking and change in the frames of references. Organizational Studies, 14, 37-59. 
Yang, K. P., Chou, C., \& Chiu, Y. J. (2014). How unlearning affects radical innovation: The dynamics of social capital and slack resources. Technological Forecasting and Social Change, 87, 152-163.

Yıldırım, A., \& Şimşek, H. (2003). Sosyal bilimlerde nitel araştırma yöntemleri. Ankara: Seçkin Yayıncılık.

Zahra, S. A., Abdelgawad, S. G., \& Tsang, E. W. (2011). Emerging multinationals venturing into developed economies: Implications for learning, unlearning, and entrepreneurial capability. Journal of Management Inquiry, 20(3), 323-330.

Zhao, Y., Lu, Y., \& Wang, X. (2013). Organizational unlearning and organizational relearning: A dynamic process of knowledge management. Journal of Knowledge Management, 17(6), 902-912. 